\title{
Case study of the real contents delivered in French motorcycle schools
}

\author{
Samuel Aupetit • Jacques Riff • Stéphane Espié • \\ Olivier Buttelli
}

Received: 23 April 2012 / Accepted: 15 May 2013 /Published online: 2 June 2013

(C) The Author(s) 2013. This article is published with open access at SpringerLink.com

\begin{abstract}
Purpose This study is concerned initial motorcycle training delivered in motorcycle schools in France. Novice motorcyclists are a particularly vulnerable group of road users in Europe and in France. However, scientific attempts to achieve a better understanding of their behaviors have been limited. The potential value of studying initial motorcycle training, both for research purposes and with regard to public policy, is readily apparent. The aims of this paper are to describe the real educational content of training in motorcycle schools and analyze to what extent this content is related to riding after licensing.

Methods A case study of all the training process of one trainee (38 hours) was carried out in real world. Audiovisual recordings and interview data of the rider and instructors were collected at each session. This study was supplemented by ethnographic observations of the educational content provided in three motorcycle schools throughout the instructors' working days.

Results The results that merged from both studies show (1) the riding skills that were fostered (i.e. control skills, and especially emergency skills, in stable and restricted environments) and undervalued (i.e. hazard perception skills, everyday skills) during initial training, and (2) the poverty of observed training settings: learners spend almost all their
\end{abstract}

\footnotetext{
S. Aupetit $(\bowtie) \cdot S$. Espié

The French Institute of Sciences and Technology for Transport, Development and Networks, University of Paris-Est, IFSTTAR, 58 boulevard Lefebvre,

75732 Paris, France

e-mail: samuel.aupetit@ifsttar.fr

J. Riff

Motor Activity and Psycho Physiological Adaptation Laboratory, University of Orléans, AMAPP, 2 allée du Château, BP 6237, 45062 Orléans Cedex 2, France

O. Buttelli

Laboratory in System Engineering, Mechanics and Energetic, University of Orléans, UPRESEA, 12 rue de Blois site Galilée, BP 6744, 45067 Orléans Cedex 2, France
}

training time riding in the same setting that is used in the test. In addition to being repeated to excess, these settings are quite different from the real traffic.

Conclusions These results are discussed regarding the scientific literature on motorcycle education. The conclusion presents the implications of these results for public policy in order to design a future rider training system.

Keywords Training $\cdot$ Motorcyclist $\cdot$ Natural context . Educational content $\cdot$ Road safety $\cdot$ Ergonomics

\section{Introduction}

The risks associated with riding powered two-wheelers are currently a major public health issue in Europe: motorcyclist mortality has been increasing since 1996 [1]. In France, the risk for motorcyclist to be killed is one the most important in European countries (with Italy and Greece): motorcycles account for $1 \%$ of motorized traffic but $40 \%$ of injured road users and almost $20 \%$ of fatalities [2]. These worrying data are especially extreme for novice riders (those who have held a licence for less than 2 years): one in five crash-involved motorcycles in France has been registered for under 1 year [3]. The potential value of studying initial motorcycle training (i.e. pretest training), both for research purposes and with regard to public policy, is readily apparent in France but also in Europe, as it may be partly responsible for the behaviour of novices and their accident rates $[4,5]$. The quality of initial rider training in EU countries is currently called into question and needs significant improvements [6, 7]. The aim of the work presented here is thus to characterize the educational content of motorcycle training in real world during the initial training given in French motorcycle schools. This investigation seeks to provide some answers to the hitherto unanswered questions: what is actually taught in initial motorcycle training? To what extent this content is related to riding after licensing? 


\subsection{The main tendencies of studies of motorcycle training}

Across the EU, initial rider training programmes vary enormously from Member State to Member State: from virtually non-existent to extensive, compulsory to voluntary, and cheap to expensive. The cost of training ranges from 400 to 3600 Euros [6]. Elsewhere in the world, there are major differences in training contents and the riding tests that validate them, and variations even exist within the same country, e.g. the United States and Australia [8].

Two kinds of studies involving motorcycle training can be identified: (a) studies that test the effectiveness of the curriculum and (b) studies that attempt to identify new educational content for motorcycle training. Research into motorcycle training ${ }^{1}$ mostly tests the effectiveness of the curriculum on the basis of the accident data for motorcyclists who have followed this curriculum and those who have not. The results tend to show that trained and untrained motorcyclists have the same risk of being involved in an accident [9-11]. Some research has attempted to demonstrate the effectiveness of training on risk level [12, 13]. Several hypotheses have been advanced to explain this ineffectiveness: (1) training focuses too much on driving skills and not enough on the cognitive and perceptive mechanisms associated with them [14], (2) the psychological characteristics of trainees are not sufficiently taken into account because most accidents are not due to a lack of driving skills but to deliberate behaviour [8], (3) training may tend to increase motorcyclists' self-confidence and not their ability to make assessments [15], (4) training rhythms are too intense to allow the stabilization and the retention of the acquired skills [16, 17]. The findings of these researches must be qualified in view of the fact that the experimental conditions are not always sufficiently controlled and the effectiveness of training should not be measured just by the number of accidents experienced by those who have undergone it [8].

The modernization of motorcycle training and licensing has recently become one of the European Union's topics for concern in the area of transport and road safety. For example, the main objective of the Initial Rider Training project, completed in 2007, was to develop a unified approach towards initial motorcycle training in Europe. A panel of five experts in motorcycle training has identified four content "blocks" (theory, motorcycle control, interactions with traffic, e-coaching) that are made up of knowledge and skills that trainees must be taught. At a national level, each country is now considering a radical modification of its current training and licensing, based on models originally developed for car driving (e.g., the GDE matrix [18]). For example, the new Norwegian motorcycle licensing system is

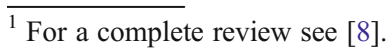

organized around three main ideas [19]: developing educational tools in order to encourage trainee self-evaluation at each stage of training, bringing into balance the teaching of cognitive and motor skills and, last, developing hazard perception in traffic conditions rather than teaching emergency skills.

Overall, the above research shows the limits of existing curricula, provides explanatory hypotheses for this ineffectiveness and proposes interesting educational possibilities. However, these advances do not make up for the lack of knowledge about proposed educational contents [20, 21], i.e. on the knowledge and skills that are actually taught and on the corresponding training settings [22, 23].

1.2 Riding seen as a situated activity and the methodological implications of this

This study refers to the "French cognitive ergonomics approach" $[24,25]$ which is at the intersection of several disciplines (cognitive anthropology, psychology and microsociology). The aim is to explore the links between context, cognition and action in the real world environment. This approach has already been applied in a number of studies and is helpful when attempting to understand teaching activities [26-28]. The first postulate is that every activity is situated because it is closely linked to the context in which it occurs [29]. In our study, each actor interacts at every moment of the training session with his or her social environment (riders, instructors, road users...) and physical environment (motorcycle, infrastructure, obstacle...). These interactions lead to behaviour that is specific to the time in question. It is therefore essential to analyze activities in real world, i.e. taking into account the social, cultural and technical conditions [25]. At a methodological level, this implies that the study must take place in "intact" or "natural" riding settings. It can be noted that at European level in the pilot study conducted in [30] SAFERIDER (2008-2010) and [31] 2BESAFE (2009-2011) several instrumented powered twowheelers were used in four EU countries in a measurement campaign conducted in real world environment.

The second postulate is that the point of view of the actors appears to be an essential unit of analysis for understanding their activities [32]. This approach places the emphasis on the collection and exploitation of interview data. The use of verbalizations as a source of observable data for the study of cognitive functioning has given rise to a considerable amount of discussion and experimental work (see the review by Nisbett and Wilson [33]). This approach suggests to collect and to combine subjective data (about the rider's experience) and objective data (on the rider's actions). While the production of data on the rider's behaviour is of value, the idea is that we can only successfully describe the riding activity if we link these objective data 
with the rider's subjective opinions. In other words, external data must be filtered through the participant's point of view. This can be possible because the individuals who are involved in training situations (instructors, riders...) acquire significant experience which can be "reactivated" and may provide useful research material.

The third postulate concerns the sample of population. The decision to study the riding activity in such a systematic and detailed manner and the complexity of the data collection procedure meant the recruitment of a relative reduced sample. It is postulated that activity and difficulties faced by studied riders can be, in part, the same as other riders in similar situations $[34,35]$. We believe that a number of experiences of the participants are shared by others. This kind of study that focuses on the details of individual experience can bring out some results which are difficult to detect with more quantitative approaches. But it is clear that increasing the number of subjects would help to achieve validation and wider applicability.

Thus, the goals of this article are (1) to describe the real educational content of motorcycle training, i.e. the skills and the knowledge taught, and (2) to analyze to what extent this content is related to riding after licensing.

\section{Material and methods}

Two studies were conducted. The main study is a case study of all the training process of one trainee (John). This is supplemented by ethnographic observations of the educational content provided in three motorcycle schools throughout the instructors' working days.

\subsection{Case study}

\subsubsection{Population}

Three instructors took part in John's training. A contract was signed with all the participants to guarantee anonymity ("external confidentiality") and data protection within the company ("internal privacy"). John is a 28 year-old rider, who held a passenger car driving license and who had some experience of riding a bicycle and a small motorized twowheeler (scooter). Because a categorization of trainees' profiles is not currently available, the studied trainers identify some typical profiles, regarding the past driving experiences of learners. The first category involves learners who have already ridden a powered two wheelers (PTW) in traffic conditions. This is especially the case of car drivers allowed to ride a motorcycle that not exceeding $125 \mathrm{cc}$. The second category concerns young riders, who use a motorcycle with engine capacity up to $125 \mathrm{cc}$ in competitive sports. The third group has rarely or not at all conducted a PTW. John is part of this latter category, which is one of the most common among trainees, according to instructors. This profile is particularly interesting because we can study all his riding experiences from a systematic analyze of its training. Finally, the fourth category is constituted by people who take the motorcycle test but do not have a car driving license. This category represents a very small portion of trainees.

\subsubsection{Procedure}

The rider's activities were investigated in a longitudinal and systematic manner in real world environment throughout the training process (as described in [36]):

- Longitudinal: data collection was conducted over a period of 5 months (November to April) (procedure inspired by Goldenbeld, Twisk and de Craen [37])

- Systematic: all the riding sessions in John's initial training were analyzed, i.e. nineteen two-hour riding sessions, making a total of 38 hours of training

- In real world: the observed situations were "natural" and "intact" training settings. The data collection system was designed to disturb the activities of the players as little as possible.

French initial motorcycle training (i.e. pre-test training) is divided into five stages: (1) controlling the motorcycle at "low" speed on a track, (2) controlling the motorcycle at "normal" speed on a track, (3) choosing the correct position, negotiating an intersection and changing direction on a road, (4) riding in traffic conditions and in urban areas, (5) recognizing dangerous situations. Stages 1 and 2 (compulsory at least $8 \mathrm{~h}$ overall) take place on a "track", which is an area $130 \mathrm{~m}$ long and $6 \mathrm{~m}$ wide (referred to as "track training" in this paper). Steps 3, 4 and 5 (compulsory at least $12 \mathrm{~h}$ overall) are performed in traffic (referred to here as "road training") and the motorcycle license is awarded after two tests. The first of these is taken at the end of track training and involves performing handling exercises at "low" speed $\left(1^{\text {st }}\right.$ gear) and "normal" speed (between 30 and $\left.40 \mathrm{~km} / \mathrm{h}\right)$. The second test takes place at the end of road training. During this, the examiner tests the motorcyclist's traffic skills in real traffic for $30 \mathrm{~min}$.

\subsubsection{Data collected/material}

During each of the trainee's riding session, audio-visual recordings of the rider's and instructor's behaviours were made and data on the participants' verbal data during and after the training sessions were collected.

Audio-visual data on the rider's and instructor's behaviours were continuously recorded during each session by an "external" camera carried by a researcher (on the track in the 
case of track training and in the instructor's following car in the case of road training) [38]. In particular, this data related to:

- The motorcyclist's behaviour: trajectory, performance, errors, effective riding time, actions (starting, falling, turning...) and verbalizations. Verbal communications with the instructor and the environmental sound sources were recorded with a microphone attached to the rider's jacket and connected to the camera by an HF device

- The instructor's behaviour: types of intervention (demonstration, feed-back, communication, verbalization)

- The proposed training situations: goals, material organization, duration.

38 hours of audio-visual recordings were collected. These data provided a full description of the training setting and a sufficient amount of material on the behaviours of the actors to carry out interviews.

Verbal data were collected either during or after the session. The data that were collected during riding is referred to as "simultaneous" and/or "interrupted" verbalization [39]. In the first case, the researcher asked the actors to "think aloud" during their activities. In the second case, the researcher asked the actors to explain their actions by asking questions which referred precisely to what had been said and done, and which did not involve generalization. This was done in this way so as to disturb training as little as possible. Just after the session, verbalization data was collected by self-confrontation interviews [25]. This method makes it possible to document precisely the player's subjective experience or immediate understanding of his/her activity. It consists of asking riders to report, at every moment, their thoughts, emotions and feelings about their behaviour in real context, when presented with the audio-visual recordings of their own activity (Fig. 1).

47 hours of self-confrontation interview were recorded (19 interviews). Verbal data acquired during the riding session are included in the amount of $38 \mathrm{~h}$ of audio-visual recordings. A final interview was conducted with the rider after the last

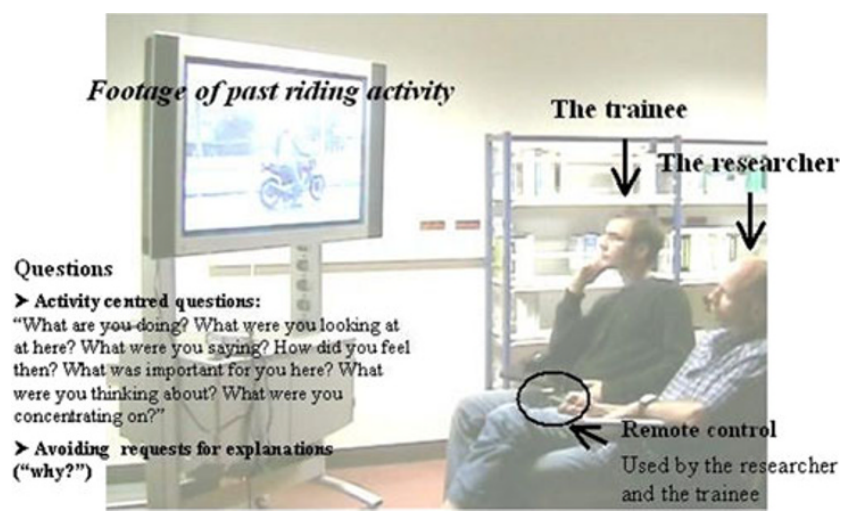

Fig. 1 The self-confrontation interview situation riding test in order to identify the skills he lacked. The motorcyclist was asked to say what he considered to be essential for post-test riding and what he had not learnt.

\subsubsection{Data processing and analysis}

All the collected data were formatted in processing grids contained two sections. These were, on one hand, the data collected during the riding sessions (audio-visual recordings of the rider's and instructor's behaviours, and the actors' verbal data during training, i.e. $38 \mathrm{~h}$ of recordings) and on the other hand, the verbal data collected after the riding sessions, by interviews (i.e. $47 \mathrm{~h}$ of recordings). The aim was to combine these two types of data in order to analyze activities in the greatest possible detail. The following information was provided in the first section: the effective time of the session, the specific behaviours of the actors (e.g. a fall), the training sessions (i.e. the type and the number of achieved exercises), and the verbal data. For the second section, the information is the effective time of the interview and the verbal data. The aim is that the verbal data can specify at each moment the observed riding session. It was made a verbatim retranscription of all the collected verbal data (during and after training sessions). The corpus contains nearly 1000 pages in A3 format.

The second stage was to decide on analysis categories for the corpus of data. These categories were chosen using a hybrid "top-down" and "bottom-up" model, i.e. the categories were the combined product of research questions concerning the educational content of riding and an initial analysis of the collected data. This procedure not only provides a basis for the development of analysis categories but also ensures that a close link with the field data is maintained [40].

\subsection{Ethnographic observations}

\subsubsection{Population}

Ten trainers who belong to three other motorcycle schools (located both in the provinces and in Paris) were studied (mean age: 41 years, mean experience in teaching: 12 years) (see Table 1). During this study, about 150 trainees were observed.

\subsubsection{Procedure}

The instructors were studied 4 months throughout their working days during training on track and training on road (the researcher was located in the following car behind the riders). 36 lessons were observed in detail $(72 \mathrm{~h})$ in the case of the first motorcycling school, 48 lessons (96 h) for the 
Table 1 Place of work, age and experience of trainers studied during the ethnographic observations

\begin{tabular}{llll}
\hline Participant & Motorcycle schools & Age & Teaching experience \\
\hline Trainer 1 & $\mathrm{N}^{\circ}$ 1 (Provinces) & 38 years & 13 years \\
Trainer 2 & $\mathrm{N}^{\circ}$ 1 (Provinces) & 44 years & 10 years \\
Trainer 3 & $\mathrm{N}^{\circ}$ 1 (Provinces) & 37 years & 1 year \\
Trainer 4 & $\mathrm{~N}^{\circ}$ 1 (Provinces) & 55 years & 29 years \\
Trainer 5 & $\mathrm{N}^{\circ}$ 2 (Provinces) & 36 years & 10 years \\
Trainer 6 & $\mathrm{N}^{\circ}$ 2 (Provinces) & 35 years & 8 years \\
Trainer 7 & $\mathrm{N}^{\circ}$ 2 (Provinces) & 39 years & 9 years \\
Trainer 8 & $\mathrm{N}^{\circ}$ 3 (Paris) & 35 years & 11 years \\
Trainer 9 & $\mathrm{N}^{\circ}$ 3 (Paris) & 44 years & 17 years \\
Trainer 10 & $\mathrm{N}^{\circ}$ 3 (Paris) & 47 years & 14 years \\
\hline
\end{tabular}

second and 28 lessons ( $84 \mathrm{~h}$, because the length of each session is $3 \mathrm{~h}$ ) for the third.

\subsubsection{Data collected/material}

The following observations were systematically made during all the courses:

- The trainers' activity: the pedagogical interventions (demonstration, feed-backs, instructions...) and the proposed situations (goals, material organization, duration...),

- The riders' activity: the type of exercise achieved, the performance (in terms of errors recorded at the licensing test), and the verbal data noted as significant.

These objective data were entered in a notebook. Verbal data of the trainers and the riders were collected by an audio-recorder.

\subsubsection{Data processing and analysis}

Data from ethnographic observations were left unchanged. They allow to describe the real contents delivered by several trainers and the behaviours of trainees in the proposed exercises. These ethnographic observations were used to assess and to supplement the results of the case study. The first task was to determine if the case study results can only be found for John or can be shared by other trainees in other motorcycle schools. This allows to validate the relevance of the identified results and to specify that they are not exclusively related to the training process of John. The second task was to combine the single case data and the ethnographic data aiming at presenting sufficiently rich examples of the corpus. Thus, although the level of the observations data is different to the case study data, the results presented in this paper merged from both these two studies. The consideration of a small number of participants (the single case study) permitted to determine some results that were systematically assessed and analysed with a larger population (the ethnographic study).

\section{Results and discussion}

The main results ${ }^{2}$ show (1) the riding skills that were fostered and undervalued during initial training and (2) the extreme poverty of the educational training settings proposed by all the studied instructors.

3.1 The riding skills that were fostered and undervalued during initial training

\subsubsection{Over-concentration on "closed skills" during track training}

The case study shows that the effective initial training of John amounted to $36 \mathrm{~h}$ of track training (18 sessions) and only $2 \mathrm{~h}$ of road training (one session). The observations highlight the considerable disparity, which we identified in all three motorcycle schools, between the length of official curricula $(8 \mathrm{~h}$ at least for the track training and $12 \mathrm{~h}$ at least for the on-road training) and those which are actually implemented (Table 2).

All the motorcycle schools observed in this study considered the journey between the school and the track, which was made for each track lesson, as road training time (this journey represents an average of $1 / 3$ of the length of track training in our study). However, our analysis highlights that the observed riders' activities during these journeys differ fundamentally from a "real" road session, in particular as regards the route. The route selected for this journey is that which presents the fewest difficulties, provides the greatest safety and takes the least time. In contrast, during a road session, the route is deliberately chosen to present trainees with difficulties.

This over-concentration on motorcycle control skills can also be shown by observing the ten instructors' concerns during the training sessions (Table 3). This can either be done either by observing (1) their interactions with learners, (2) their interpretations and explanations of riders' behaviour, (3) the focus and direction of their attention.

This table shows that the instructors' activities during the initial training sessions are determined by 12 themes ( 7 themes for track training and 5 for road training). The themes that have been identified for track training and road training are different, except for "Speed". The concerns of instructors are therefore different in traffic from during track training, being more

\footnotetext{
${ }^{2}$ For a better readability, each type of result is discussed just after its presentation.
} 
Table 2 Mean length of real initial training in the three studied motorcycle schools

\begin{tabular}{llll}
\hline & Length of track training & Length of road training & Total length of training \\
\hline Motorcycle school 1 & $23 \mathrm{~h}$ & $8 \mathrm{~h}$ & $31 \mathrm{~h}$ \\
Motorcycle school 2 & $26 \mathrm{~h}$ & $2 \mathrm{~h}$ & $28 \mathrm{~h}$ \\
Motorcycle school 3 & $27 \mathrm{~h}$ & $6 \mathrm{~h}$ & $33 \mathrm{~h}$ \\
\hline
\end{tabular}

concerned with control of the vehicle (5 of the 7 themes): "Posture", "Speed", "Trajectory", "Cornering", and "Use of motorcycle controls". On the contrary, most of the instructors' comments during the road ride were concerned with the relationship with other road users and handling of the motorcycle (4 categories of 5): "Route", "Signals", "Visual checks", and "Road position".

Nevertheless, the verbal data collected from instructors during ethnographic observations show that they are aware that initial training was concentrated on the track, and that they make an effort to recontextualize the skills taught on track to riding in traffic by getting the riders to use their imagination:

"Now that you know how to accelerate and brake, you are going to try to imagine that you are in traffic!" (Trainer 8)

"On the track, you will brake, downshift and accelerate as if you were at a stop sign in the real life!" (Trainer 2)

Table 3 Concerns that determine the instructor's activities

\begin{tabular}{|c|c|}
\hline Concerns with rider's & Examples of verbal interventions extracted from the case-study \\
\hline \multicolumn{2}{|l|}{ Track training } \\
\hline Gaze direction & $\begin{array}{l}\left.\text { "Look at the markers on the left when you're turning!" (Session n }{ }^{\circ}, 75^{\prime}\right) \\
\left.\text { "Don't look at the markers in the slalom or you'll hit them!" (Session n }{ }^{\circ} 8,47^{\prime}\right)\end{array}$ \\
\hline Posture & $\begin{array}{l}\left.\text { "Keep your legs on the tank!" (Session }{ }^{\circ} 1,54^{\prime}\right) \\
\text { "Relax the upper body! You're stiff as a ramrod!"(Session n4, 29') }\end{array}$ \\
\hline Speed & $\begin{array}{l}\left.\text { "Accelerate! Accelerate in the slalom!" (Session n }{ }^{\circ}, 9^{\prime}\right) \\
\left.\text { "You’re going too fast! Slow down! Your main problem on this course is your speed." (Session n } 17,29^{\prime}\right)\end{array}$ \\
\hline Trajectory & $\begin{array}{l}\text { "You have to take at each time the outside plot of the door in the low speed exercise!" (Session n }{ }^{\circ} 8,30^{\prime} \text { ) } \\
\left.\text { "Your trajectory on the bend is incorrect! You need to turn more!" (Session n }{ }^{\circ} 17,87^{\prime}\right)\end{array}$ \\
\hline Cornering & $\begin{array}{l}\text { "You are tilting the motorbike at the right angle here! But you should have stayed longer in that position } \\
\text { to succeed" (Session } n^{\circ} 10,54^{\prime} \text { ) } \\
\text { "As soon as you tilt a little, you restore the balance immediately! You can tilt over, the motorbike won’t } \\
\text { fall over!" (Session n' } 11,58^{\prime} \text { ) }\end{array}$ \\
\hline Performance & $\begin{array}{l}\left.\text { "You took } 21 \text { '36 on this normal speed course!" (Session n }{ }^{\circ} 17,102^{\prime}\right) \\
\left.\text { "You brushed against a marker so you only got a B in the test!" (Session n }{ }^{\circ} 18,41^{\prime}\right)\end{array}$ \\
\hline Use of motorcycle controls & $\begin{array}{l}\text { "You didn’t use the rear brake in your emergency braking maneuver!" (Session nº, 93') } \\
\text { "Declutch! Declutch! Use your clutch more!" (Session n } 16,80^{\prime} \text { ) }\end{array}$ \\
\hline \multicolumn{2}{|l|}{ Road training } \\
\hline Route & $\begin{array}{l}\left.\text { "Take the second exit on the roundabout." (Session n' } 19,18^{\prime}\right) \\
\left.\text { "Take the road to the motorway at the next intersection." (Session n }{ }^{\circ} 19,24^{\prime}\right)\end{array}$ \\
\hline Signaling & $\begin{array}{l}\text { "John you really must indicate when you want to overtake!" (Session n¹9, 39') } \\
\text { "You do not indicate early enough to show your direction before the roundabout!" (Session n } 19,45^{\prime} \text { ) }\end{array}$ \\
\hline Visual checks & $\begin{array}{l}\text { "You didn't look at the blind spot on the roundabout! You must look right if no vehicle is overtaking you!" } \\
\text { (Session } n^{\circ} 19,59^{\prime} \text { ) } \\
\text { "Show me clearly that you look right and left at the stop line." (Session } n^{\circ} 19,86^{\prime} \text { ) }\end{array}$ \\
\hline Position on road & $\begin{array}{l}\text { "If you want to turn left at the next intersection, you must move into the middle of the road!" } \\
\text { (Session } n^{\circ} 19,30^{\prime} \text { ) } \\
\left.\text { "You are badly placed on the roundabout to turn right." (Session } n^{\circ} 19,67^{\prime}\right)\end{array}$ \\
\hline Speed & $\begin{array}{l}\text { "The speed limit in this area is } 30 \mathrm{~km} / \mathrm{h} \text { and you are doing } 40 \text {, so slow down!" (Session n }{ }^{\circ} 19,47^{\prime} \text { ) } \\
\text { "You can accelerate to free up the intersection!" (Session } \mathrm{n}^{\circ} 19,61^{\prime} \text { ) }\end{array}$ \\
\hline
\end{tabular}


by referring to the traffic context where the skill can be used:

"This slalom task is to help you to ride in traffic at very slow speed, when you ride between cars and very close to them" (Trainer 6)

"I am teaching you the obstacle avoidance technique because it is very useful on the road; you have to master this skill after licensing when the traffic is very dense" (Trainer 7)

"Let's imagine that a car door opens just in front of you and that you are forced to take an evasive action!"

(Trainer 10)

or by highlighting the similarity between the track and real riding situations:

"Take a lot of care over the turn maneuver on the training track because the carriageway is $6 \mathrm{~m}$ wide, like the carriageway of a real road" (Trainer 5)

"If you do not manage to make a U-turn on the track, you will not be able to do it in real life because the size of the carriageway is the same than in traffic context!" (Trainer 9)

At the analysis, this focus of track training can be questioned in terms of the developed skills. Since Poulton [41], the literature on motor learning has distinguished between two main types of skills. The first, so-called "closed skills", are developed in hazard-free predictable environments with a high degree of spatial and temporal stability. Actions are not affected by environmental changes, tend to be habitual and the individuals performing them know exactly what to do and when. Track training provides such environments, the "track" is a relatively closed situation (the course does not change, obstacles are positioned in the same way, and there are no other users ...) and learning in this context involves learning and stabilizing appropriate motor coordination (maintaining a constant speed, operating the motorcycle controls, positioning of the motorcycle...). In contrast, other skills are developed in "changing" and "dynamic" environments, where actions must be continuously modified to suit the context. This is the case with riding in real traffic where the rider has to cope with dynamic situations (presence of other road users, unusual infrastructure, varying weather conditions and varying traffic density). These skills are called "open skills" and mainly involve perceptive mechanisms, which are almost absent in closed skills (awareness of the situation and risk, anticipation, information processing, decision-making). These open skills represent an important adaptive and responsive element of motorcycle riding activity. Based on this distinction, we can conclude that the teaching of closed skills, and therefore the development of motor abilities in a stable environment, is clearly overvalued in the studied initial motorcycle training to the detriment of the teaching of open skills.

These data also confirm the hypotheses put forward by a lot of authors [42-45] that initial training concentrates on the ability to control the motorcycle to the detriment of hazard perception skills. For Allardice [46], the perceptual skills concerning the handling of the various elements of the real driving situation are often undervalued in motorcycle training systems. The problem is that the lack of control skills for novice riders is not the most important element involved in the occurrence of accidents [47]. According to MAIDS [48], failures in rider hazard perception are involved in more accidents than motorcycle control. For example, when riders are responsible for an accident, their most frequent errors relate to the perception of the hazard (in $36.6 \%$ of cases) and errors of traffic analysis (in $27.7 \%$ of cases).

\subsubsection{The focus on teaching skills rarely used in traffic conditions to the detriment of frequently used skills}

The interview conducted after the final test session shows what John considered missing after initial training (Fig. 2).

Several elements of understanding of this classification can be put forward:

- Road training is undervalued. Throughout his training, John never used a road with a speed limit of over $90 \mathrm{~km} / \mathrm{h}$, as all the trainees we observed during the $252 \mathrm{~h}$ of the ethnographic observations. Trainee's experience of taking tight curves is therefore extremely limited in all the observed motorcycle schools

- In the case of some skills ("putting the motorcycle on its stand", "pushing the machine", "riding with a passenger", "using the rear brake") the requirement for obtaining a license is not sufficient. For example, to show that he was able ride with a passenger John merely had to ride $15 \mathrm{~m}$ in a straight line in first gear. In view of this, it is not surprising that only $3 \mathrm{~min}$ of his training process (from the $32^{\text {nd }}$ to the $35^{\text {th }}$ minute of the $12^{\text {th }}$ session) were spent on this task. This was John's
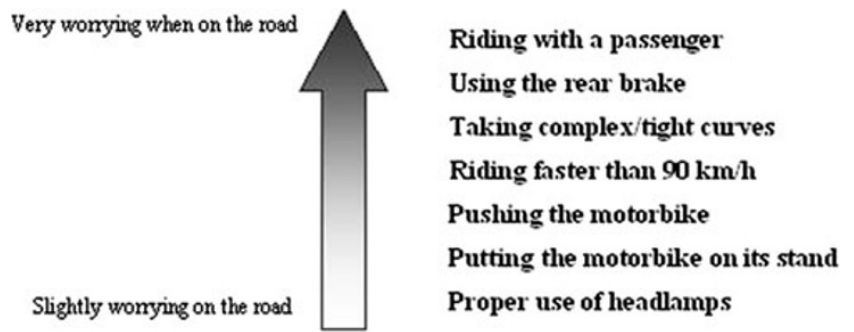

Fig. 2 Classification of "missing skills": riding skills considered by the studied rider to be missing after initial training 
only experience of riding with a passenger in all his initial training. It is not difficult to understand why he and the majority of interviewed learners of this study think that they will be uncomfortable with this task after licensing

- For emergency skills the requirement for obtaining a license is too high. These skills require a long learning process for John and all the studied motorcyclists. Most of the learner's training time is spent re-experiencing the settings which develop these skills.

These results highlight the fact that the observed motorcycle schools focus on teaching skills rarely used in traffic conditions to the detriment of frequently used skills. The problem is that these emergency skills appear to be required in fairly rare situations in real traffic conditions, while the "missing skills" identified by John and other learners seem to be used daily. Moreover, recent theories on the retention of motor skills (for a review see [49]) suggest that because of the scarcity of the situations where these emergency skills are used, the underlying motor coordination is likely to be unlearnt and lost once the rider has a license, due to insufficient reinforcement. This is why in Europe (especially in Norway and Finland) it has recently been decided that the motorcycle test should concentrate on developing hazard perception rather than technical competence with regard to emergency skills [19].

\subsection{The extreme poverty of proposed training settings}

\subsubsection{Repetition as the only teaching strategy}

The recorded data indicate that most of the track situations that are proposed in all the motorcycle schools develop the ability to maneuver and control the motorcycle at "low" speed (first gear) (Fig. 3) and "normal" speed $(30 / 40 \mathrm{~km} / \mathrm{h})$ (Fig. 4) by means of exercises with obstacles (markers, stakes).

The "low speed" handling exercise was performed 400 times and the "normal speed" handling exercise 189 times during John's training (see Fig. 5).

The same tendencies were recorded during the ethnographic observations made in the three motorcycle schools. The main teaching strategy used by all the instructors we observed was repetition. It is as though coordination and control can only be acquired by excessive repetition of these courses. Although repetition is a valid educational method, merely repeating the same pattern of movement would seem to be too limited, as the learners seemed to have realized:

"I have been doing the same exercise for $90 \mathrm{~min}$ ! I'm tired. My left wrist hurts from using the clutch!" (John, session 6)

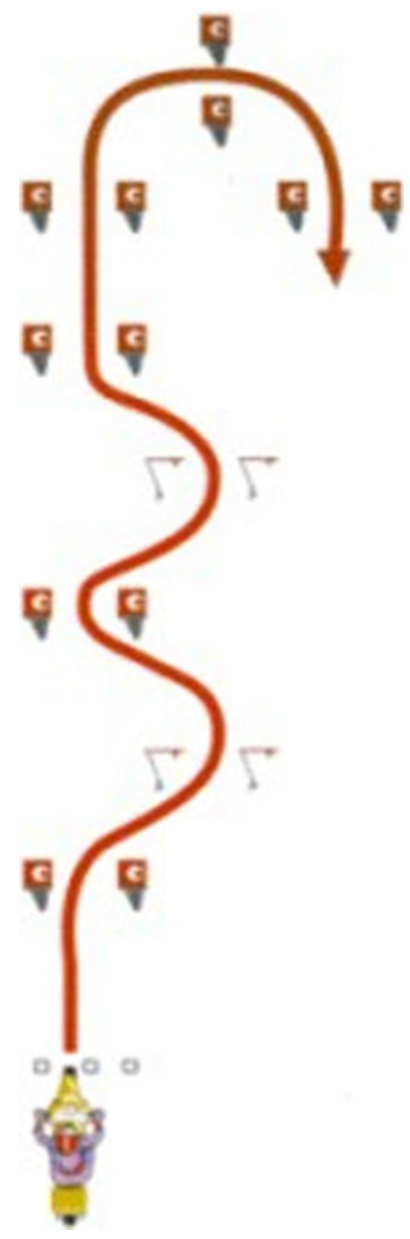

Fig. 3 "Low speed" handling exercise

"I want to do something else! I can do this exercise perfectly but I repeat again and again the same thing!" (John, session 8)

"I was so bored repeating the same exercise that I decided to stop! I took the motorbike to the side of the track and stopped! (John, session 12)

"I don't understand why the instructor doesn't change this exercise! I haven't made a mistake since the beginning of the lesson!" (Learners interviewed during the ethnographic observations) "I was getting so tired because of the repetition that I couldn't concentrate any more. I was starting to make mistakes and it was getting dangerous!" (Learners interviewed during the ethnographic observations)

At the analysis, these results show that the main educative strategy used in the studied training systems is the repetition. It seems to indicate that motor coordination can only be acquired by the excessive repetition of these exercises. While repetition is a relevant teaching method [50], the strategy of the trainer which consists in seeking only the repetition of gestures is limited [51]. Indeed, the educational situation that considers the repetition as the exclusive 


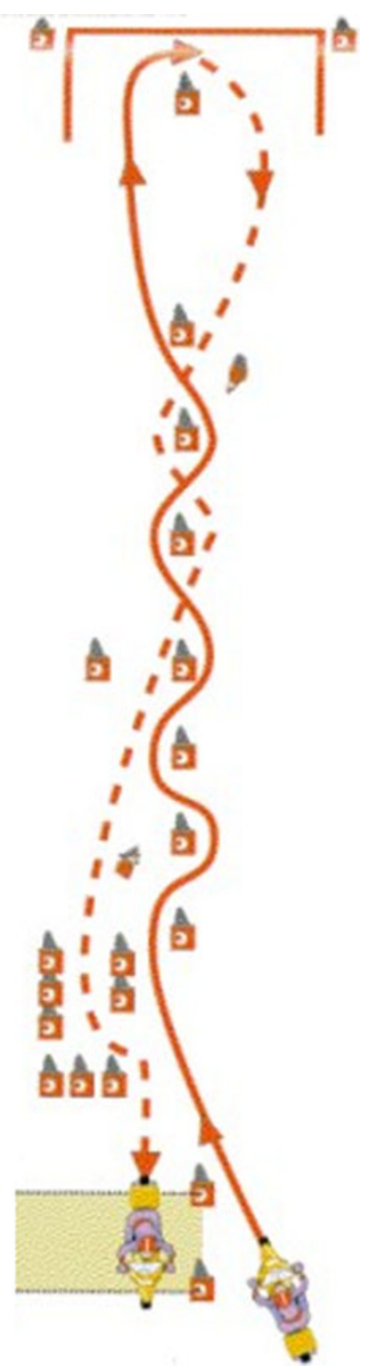

Fig. 4 "Normal speed" handling exercise

modality of learning includes a number of drawbacks. This is not the most efficient method regarding the learning theories; it causes a lack of interest and annoyance for learners, which appear to be unfavourable for learning and their engagement in the training process.

\subsubsection{Test settings as the only training situations}

The observations carried out in all the motorcycle schools showed that the two main training situations ("low" and "normal" speed handling exercises) were performed on reproductions of test tracks. Thus, right from the start of their training, the trainees performed exercises that were as complex as those in the track test. Few original training situations, i.e. exercises that are not on the list of those requested for the track test, were devised. "Waving" (balancing exercise) and the "slalom" (counter steering exercise) which John was asked to perform during his first two lessons were the only one training situations which could not figure in the licensing test. Our data indicate that these situations represented less than $19 \%$ of the studied rider's effective track training time, and less than $6 \%$ if we exclude the first two lessons. So John spent $81 \%$ of his effective track training time on "low" and "normal" speed handling exercises (Table 4). This figure rises to $98 \%$ when we consider the training settings implemented by all the instructors observed in the three motorcycle schools.

Overall, the results tend to show that the track training situations were identical to track test situations. Very few training settings were designed with reference to the learner's progress and difficulties. Unlike Australian motorcycle instructors [21], the instructors observed in our study did not identify individual learning needs and did not use a range of educational techniques. For example, John thus experienced the settings used in the licensing test 589 times. As track training represents almost all the initial training, we can say that John's training was more likely to prepare him for a track test than to teach him how to ride in real traffic conditions. These results are consistent with Haworth and Mulvihill [8], who highlight that the majority of motorcycle training systems are dedicated to preparing trainees for licensing, so that the learning settings proposed by instructors are the same handling situations they will encounter during the test.

\subsubsection{Educational settings that are far removed from real traffic: the example of obstacle avoidance}

The field data highlight that in initial training, emergency techniques, and more particularly the obstacle avoidance maneuver, are taught in a relatively controlled and stable setting. The speed is fixed at $40 \mathrm{~km} / \mathrm{h}$, training takes place on the usual track and course and the situation is shown by fixed markers. The rider knows exactly where, when and how he has to avoid the markers. A number of statements by the instructors illustrate this disparity between the avoidance maneuver performed in training and in traffic:

"If you ever have an avoidance problem during training, just continue in a straight line! You are not in traffic conditions!" (Trainer 1)

"It is not a real door that has opened in the avoidance corridor: this is not a real avoidance situation so I don't want you to brake suddenly! I know this situation is not really an obstacle avoidance situation, I am just teaching you the mechanisms of avoidance!" (Trainer 3)

"You made your avoidance maneuver too soon! You were positioned to the left of the lane to avoid an obstacle to the right of it! We are not in real traffic, but try to not anticipate too much!" (Trainer 4) 
Fig. 5 Number of "low" and "normal speed" handling exercises performed during John's track training

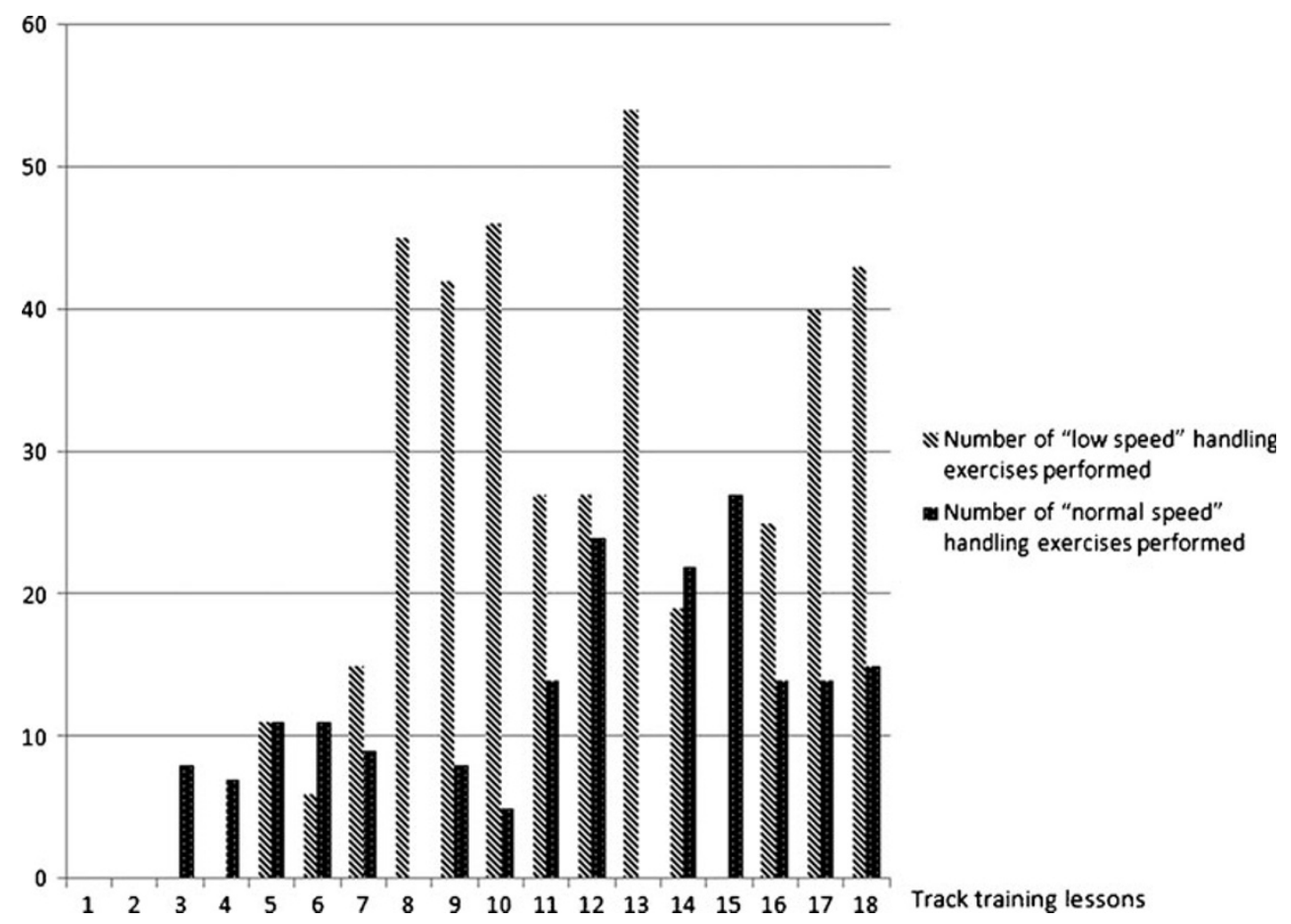

"The avoidance I'm presenting you with today has been completely prepared in advance! You know what speed to ride at, you know how and when to slow down, push on your right handlebar and restore the balance." (Trainer 7)

"The distance between markers has been carefully chosen so you have enough time to cut the gas, avoid the obstacle and bring the motorbike to the center of the track... so you don't need to hurry, it is not a real situation!" (Trainer 8)

These data seem to assume that the avoidance maneuver, which is one of the main skills taught, is performed in a totally different manner in real traffic conditions than during training. In reality, it is required unexpectedly in environments which are made hazardous by the traffic and in rare and dangerous settings. The educational situation seems to be far removed from post-test riding. The adaptation of a real riding setting to a training setting, and its necessary decontextualization, seems to be done without considering the basic characteristics of obstacle avoidance such as the hazard perception dimension. These two situations appear so different that John and other trainees seem to learn something other than real obstacle avoidance skills in initial training. The issue of the transfer of skill from training situations to real riding is posed.

To sum up, this disparity between the obstacle avoidance situation that is taught in training and that which is really required in traffic conditions may be detrimental to novice riders if they believe that when they have mastered the avoidance manoeuvre in track training they have been trained to perform it in traffic. We can make the hypothesis that (1) the gap between training and real riding situations, (2) the focus of training systems on the repetition of these decontextualized situations and (3) the fact that motorcycle test checks and promotes the success of the rider in these settings, can participate in the emergence of a phenomenon called "over-confidence", which represents a potential danger for novices $[18,52]$. In-depth study of this phenomenon after licensing must be carried out to confirm the results of Rowden and Watson [53] which show how novice riders tend to engage in risky situations, believing wrongly that they have acquired the skills to master such situations. As

Table 4 Number of repetitions, total length and effective time of the low and normal speed handling exercises made by John during his initial training

\begin{tabular}{lll}
\hline & "Low” speed handling exercise & "Normal” speed handling exercise \\
\hline Number of repetitions & 400 & 189 \\
Total length & $9 \mathrm{~h} 40$ & $10 \mathrm{~h} 10$ \\
Percentage of effective track training time & $39 \%$ & $42 \%$ \\
\hline
\end{tabular}


Haworth and Mulvihill [8], and if "over-confidence" is recognised as significant, we suggest to take into account this phenomenon in designing new motorcycle training systems in order to make novice riders safer.

\section{Conclusion}

This study has allowed to describe and to characterize the educational content of the motorcycle initial training proposed by the instructors we observed. The results show that the riding skills which are taught are essentially closed skills related to motorcycle control in stable and restricted environments, with the instructors' activity massively focused on vehicle control. In addition, initial training seems to concentrate on teaching a number of emergency skills while several necessary everyday skills have not been acquired at the end of training. In general, the training settings used by instructors lack originality and educational value; trainees spend almost all their track training time riding in the same setting that is used in the track test. In addition to being repeated to excess, these training settings are quite different from the situations encountered in traffic. This indicates that trainees learn riding skills that are "decontextualized" in their initial training. These results suggest the need for more thorough investigations into the learning and teaching of motorcycle riding, and with a larger population, in order to assess to what extent the currently proposed educational contents and the skills they develop are in line with real post-test riding. This is the core of an on-going French broad research programme [54], which is the continuation of the study presented in this paper. This programme aims at proposing rider training and licensing guidelines based on a naturalistic study of novices' behaviour. This study consists in a systematic monitoring of all the trips made by riders for two months after passing the test. Three methods are applied: diaries (where the motorcyclists are asked to note down the situations they experience during their journeys which are or can be problematic), instrumentation in sensors, GPS system and four cameras implemented on the riders' own motorbike to record vehicle-based data, and selfconfrontation interviews. All these data will be combined to set out the problems encounter by novices after passing the test and identify how the limitations of the existing training and licensing system are link with these problems.

This study was conducted in an atmosphere of discussion around the rider's license. The third European Directive on driving licenses provides from 2013 changes in motorcycle licensing. This Directive requires each EU country to design its specific licensing situations on the basis of the test of several skills (e.g. an avoidance maneuver at $50 \mathrm{~km} / \mathrm{h}$ ). Each EU country and France in particular, is so busy thinking about the design of these settings. Thus the interests for the authorities of the present results are: (1) the test of a methodology to describe the actual educational content that allows auditing the training system (such audit deserves a much larger population), and (2) the identification of a number of elements that have to be improved in the future licensing system. These elements are first the fact that the training situations are the licensing settings, and thus, the choice of the future test situations largely dictate the nature of the delivered training. The instructors only prepare students to get the license. Secondly, the results showed that there could be a gap between the compulsory training program and its application. It is therefore necessary to monitor its implementation and not to focus only on the theoretical aspect. Thirdly, it seems also necessary to promote the development of hazard perceptual skills as they are traditionally undervalued in observed motorcycle-schools and yet involved in lots of accidents. Fourthly, it appears to us essential to balance the teaching of control and perceptual dimensions: these two dimensions are required in real traffic conditions at each moment but in different proportions depending traffic situations. So these both dimensions must be taught during initial training. Finally, one of the challenges of the authorities is to reduce the gap between the training/licensing situations and the real riding situations. The goal is to ensure that the riders' activity in training settings seeking similar mechanisms to those used in traffic conditions.

Going beyond the specific issue of motorcycle training, these findings reveal a shortage of empirical data about riding behaviour in general (for details see [30]). The few field studies that deal with motorcyclists in traffic and their interactions with other road users are insufficient to provide an understanding of the specific nature of this type of transport and to permit the development of a relevant riding behaviour model. Yet we feel that it is important, even necessary, to have a specific model for motorcycle riding in order to improve initial training. How can we define relevant educational contents without precise knowledge about motorcycle riding in real context? We cannot be satisfied with superficial adaptations of models originally developed for driving (e.g. matrix GDE, 2003). Thus, future researches should be conducted in real traffic conditions, in line with the naturalistic study carried out in [30] or [31], aiming notably at contributing to the development of a riding behaviour model.

Acknowledgements This study was conducted as part of work on a doctoral thesis jointly funded by the Fondation MAIF and the Région Centre, under the direction of the University of Orléans and INRETS (French National Institute for Transport and Safety Research), which has now become IFSTTAR. The authors are grateful to all the motorcycle schools that have participated.

Open Access This article is distributed under the terms of the Creative Commons Attribution License which permits any use, distribution, and reproduction in any medium, provided the original author(s) and the source are credited. 


\section{References}

1. CARE (2007) European road accident database

2. DACOTA (2010-2012) Data collection transfert and analysis. European Commission

3. ONISR (2009) Observatoire national Interministériel de la Sécurité Routière

4. Rutter DR, Quine L (1996) Age and experience in motorcycling safety. Accid Anal Prev 28:15-23

5. McCartt AT, Mayhew DR, Braitman KA, Ferguson SA, Simpson HM (2009) Effects of age and experience on young driver crashes: Review of recent literature. Traf Inj Prev 10(3):209-2193

6. IRT (2004-2007) The initial rider training project. ACEM (The Motorcycle Industry in Europe)/FEMA (The Federation of European Motorcyclists' Associations)

7. TRAIN-ALL (2006-2009) Integrated system for driver TRaining and assessment using interactive education tools and new training curricula for ALL modes of road transport. European Commission (6th FP)

8. Haworth N, Mulvihill C (2005) Review of motorcycle licensing and training. Monash University Accident Research Centre report 240, Melbourne

9. Mortimer RG (1988) A further evaluation of the motorcycle rider course. J Saf Res 19:187-196

10. Mayhew DR, Simpson HM (1996) The effectiveness and role of driver education and training in a graduated licensing system. Traffic Injury Research Foundation, Ottawa

11. Mayhew DR, Simpson HM, Robinson A (2002) The safety value of driver education and training. Inj Prev 8:3-8

12. McDavid JC, Lohrmann BA, Lohrmann G (1989) Does motorcycle training reduce accidents? Evidence from a longitudinal quasiexperimental study. J Saf Res 20(2):61-72

13. Billheimer JW (1998) Evaluation of the California motorcyclist safety program. Transp Res Rec 1640:100-109

14. Liu CC, Hosking SG, Lenné MG (2009) Hazard perception abilities of experienced and novice motorcyclists: An interactive simulator experiment. Transp Res F 12:325-334

15. Elliot M, Baughan C, Broughton J, Chinn B, Grayson G, Knowles J, Smith L, Simpson H (2003) Motorcycle safety: A scoping study. Crowthorne: TRL report 581, Transport Research Laboratory.

16. Maxwell GS (1985) Problems in being responsive: Reflections on an evaluation of a program for training motorcycle riders. Eval Prog Plan 8:339-347

17. Christie R (2001) The effectiveness of driver training as a road safety measure: A review of the literature. Royal Automobile Club of Victoria, Noble Park

18. Hatakka M, Keskinen E, Gregersen NP, Glad A, Hernetkoski K (1999) Results of EU project GADGET. In: Siegrist S (ed) Driver training, testing and licensing towards theory based management of young drivers' injury risk in road traffic (WP3). Berne, BFU report 40.

19. Lund BA (2006) New rider training system in Norway. Proceedings of the International Motorcycle Safety Conference, Long Beach

20. Baldi S, Baer JD, Cook AL (2005) Identifying best practices states in motorcycle rider education and licensing. J Saf Res 36:19-32

21. Rowden PJ, Watson BC, Haworth NL (2007) What can riders tell us about motorcycle rider training? A view from the other side of the fence. Australasian Road Safety Research, Policing and Education Conference, Melbourne

22. Hébrard A (1986) L'éducation physique et sportive: Réflexions et perspectives. Revue EPS, Paris

23. Marsenach J, Mérand R (2003) Regard porté sur la recherche en didactique de l'éducation physique et sportive. In: Amade-Escot C (ed) Didactique de l'EPS, état des recherches. Paris, Revue EPS, pp 367-383

24. Ombredane A, Faverge JM (1955) L'analyse du travail. PUF, Paris
25. Theureau J (2003) Course of action analysis and course of action centered design. In: Hollnagel E (ed) Hanbook of cognitive task design (Chapter 4). Lawrence Erlbaum Associates, Mahwah

26. Vion M, Perez S, Theureau J (2000) Apprendre avec autrui : aide ou gêne au développement des compétences de l'apprenant ? 35ème Congrès de la Société d'Ergonomie de Langue de Française, «Communication et Travail », Toulouse

27. Sève C, Leblanc S (2003) Exploration et exécution en situation: Singularité des actions, construction de types et apprentissage dans deux contextes différents. Rech et Form 42:63-74

28. Aupetit S, Espié S, Larnaudie B, Riff J, Buttelli O (2011) Tools and methodologies for the study of motorcyclist's behaviour in real context. Adv Transp Stud 24:15-22

29. Lave J, Wenger E (1991) Situated learning: Legitimate peripheral participation. Cambridge University Press, Cambridge

30. 2BESAFE (2009-2011) Two wheeler behaviour and safety. European Commission (7th FP).

31. SAFERIDER (2008-2010) Advanced telematics for enhancing the safety and comfort of motorcycle riders. European Commission (7th FP).

32. Bannon L (1991) From human Factor to Human Actor. In: Greebaum J, Kyng M (eds) Design at work: Cooperative design of computer systems. Mahwah, LEA, pp 27-44

33. Nisbett R, Wilson T (1977) Telling more than we can know: Verbal reports on mental processes. Psychol Rev 84:231-259

34. Clot Y (1999) La fonction psychologique du travail. PUF, Paris

35. Leblanc S, Ria L, Dieumegard G, Serres G, Durand M (2008) Concevoir des dispositifs de formation professionnelle des enseignants à partir de l'analyse de l'activité dans une approche enactive. Activités 5(1):58-78

36. Saad F (1999) Analyses of drivers' activity in real driving conditions: theoretical and methodological issues. First Internationnal DRiiVE Workshop, July 21-23, Espoo, Finland.

37. Goldenbeld C, Twisk D, de Craen S (2004) Short and long term effects of moped rider training: a field experiment. Transp Res F 7:1-16

38. Pauzié A, Gelau C, Aupetit S (2009) Safety evaluation methodology of ITS for riders. International Conference on Models and Technology for Intelligent Transportation Systems, June 22-23, Rome, Italy.

39. Theureau J, Jeffroy J (1994) Ergonomie des situations informatisées. Toulouse, Octarès

40. Glaser B, Strauss A (1967) The discovery of grounded theory. Adeline, Chicago

41. Poulton EC (1957) On prediction in skilled movement. Psychol B $54: 467-478$

42. Crick J, McKenna FP (1991) Hazard perception: can it be trained? In: G.B. Grayson (ed.), Behavioural Research in Road Safety (pp. 100-107). Proceedings of a seminar at Manchester University, September. Crowthorne, Berkshire, England, pp 17-18

43. Chesham DJ, Rutter DR, Quine L (1993) Motorcycling safety research: a review of the social and behavioral literature. Soc Sci Med 37(3):419-429

44. Reeder AI, Chalmers DJ, Langley JD (1996) Rider training, reasons for riding, and the social context of riding among young on road motorcyclists. Aust NZ J Publ Heal 20:369-374

45. Haworth N, Smith R, Kowadlo N (2000) Evaluation of rider training curriculum in Victoria. Report 165. Melbourne, Monash University Accident Research Centre.

46. Allardice G (2002) The biker's bible. Fun and survival on roadgoing motorcycles. Grant Sheehan, Phantom House Books, Wellington

47. Rothe JP, Cooper PJ (1988) Motorcyclists: who are they and why they do what they do. Transp Res Rec 1168:78-85

48. MAIDS (2003) Motorcycle accidents in depth study. ACEM (The Motorcycle Industry in Europe).

49. Savion-Lemieux T, Penhune VB (2005) The effects of practice and delay on motor skill learning and retention. Exp Brain Res 161:423-431 
50. Famose JP (1983) Stratégies pédagogiques, tâches motrices et traitement de l'information. Dossiers EPS 1:9-21

51. Meltzer J (1990) Conception et proposition de contenus d'enseignement en 4e-3e. Spirales 3:133-151

52. Gregersen NP (1996) Young drivers' overestimation of their own skill. An experiment on the relation between training strategy and skill Accid Anal Prev 28(2):243-250
53. Rowden PJ, Watson BC (2008) Motorcycle rider training and perceptions of skill. Australasian Road Safety Research, Policing and Education Conference, November 9-12, Adelaide, South Australia.

54. SIM2CO $+(2011-2013)$ Design of motorcycle training modules including simulation to the development of hazard perception skills. The French National Research Agency. 